\title{
EXOGENOUSLY APPLIED D-PINITOL AND D-CHIRO-INOSITOL MODIFIES THE ACCUMULATION OF $\alpha$-D-GALACTOSIDES IN DEVELOPING TINY VETCH (VICIA HIRSUTA [L.] S.F. GRAY) SEEDS
}

\author{
LESŁAW B. LAHUTA ${ }^{1}$, MARCIN HoRBOWICZ ${ }^{2}$, Ewa GOJŁO ${ }^{1}$, \\ JOANNA GOSZCZYŃSKA ${ }^{1}$, RYSZARD J. GÓRECKI ${ }^{1}$ \\ ${ }^{1}$ Department of Plant Physiology and Biotechnology, University of Warmia and Mazury \\ Oczapowskiego 1A, 10-718 Olsztyn, Poland \\ e-mail: lahuta@uwm.edu.pl \\ 2 Vegetable Quality Laboratory, Research Institute of Vegetable Crops \\ Konstytucji 3 Maja 1/3, 96-100 Skierniewice, Poland
}

(Received: March 9, 2005. Accepted: June 23, 2005)

\begin{abstract}
In the present study we have investigated the effect of exogenous cyclitols on the accumulation of their galactosides and raffinose family oligosaccharides (RFOs), as well as on some enzymes important for their biosynthesis in seeds of tiny vetch (Vicia hirsuta [L.] S.F. Gray). Immature seeds during 6-day incubation with D-chiro-inositol (naturally does not appear in seeds of tiny vetch) were accumulated cyclitol and its galactosides (fagopyritols: B1 and B2). Short 4-hour incubation with D-chiro-inositol, and subsequent slow desiccation process caused accumulation of free cyclitol only, without biosynthesis of its galactosides. Feeding D-chiro-inositol to pods of tiny vetch induced accumulation of high levels of its galactosides (fagopyritol B1, B2 and B3) in maturing seeds. Similarly, feeding D-pinitol increased accumulation of its mono-, di- and tri-galactosides: GPA, GPB, DGPA and TGPA in tiny vetch seed. Accumulation of both cyclitols and their galactosides drastically reduced accumulation of verbascose. Inhibition of RFOs biosynthesis by elevated levels of free cyclitols suggests some competition between formation of both types of galactosides and similarity of both biosynthetic routes in tiny vetch seeds. Galactinol synthase (GolS) from tiny vetch seeds demonstrated ability to utilize D-chiro-inositol as galactosyl acceptor, instead of myoinositol. Presence of both cyclitols, as substrates for GolS, caused synthesis of their galactosides: fagopyritol B1 and galactinol. However, formation of galactinol was more efficient than fagopyritol B1. D-chiro-Inositol and D-pinitol at concentrations several-fold higher than myo-inositol had inhibitory effect on GolS. Thus, we suggest that a level of free cyclitols can have an influence on the rate of galactinol biosynthesis and further accumulation of RFOs and galactosyl cyclitols in tiny vetch seeds.
\end{abstract}

KEY WORDS: D-chiro-inositol, D-pinitol, raffinose, stachyose, verbascose, galactinol synthase, Vicia hirsuta, seed.

\section{INTRODUCTION}

Raffinose family oligosaccharides (RFOs) comprises: raffinose, stachyose, and verbascose, containing 1, 2 and 3 galactosyl moieties in a molecule, respectively. Beside RFOs, seeds of many species contain $\alpha$-galactosides of myo-inositol, D-pinitol, D-chiro-inositol, D-ononitol and

\section{Abbreviations:}

RFOs - raffinose family oligosaccharides; Gal-C - $\alpha$-galactosides of cyclitols; GolS - galactinol synthase; FB1S - fagopyritol B1 synthase; RS - raffinose synthase; STS - stachyose synthase; fagopyritols - $\alpha$-galactosides of D-chiro-inositol; GPA galactopinitol A; GPB - galactopinitol B; DGPA - di-galactopinitol A (ciceritol); TGPA - tri-galactopinitol A; DAF - day after flowering; FW - fresh weight; DW dry weight
D-bornesitol (Yasui et al. 1987; Horbowicz and Obendorf 1994; Peterbauer and Richter 1998; Lahuta et al. 2001; Obendorf et al. 2005). Both types of carbohydrate have been implicated in the seed defense system against damage due to rapid dehydration during seed maturation and/or long storage processes, although full explanation of the physiological roles needs further studies (Obendorf 1997; Peterbauer and Richter 2001).

Biosynthesis of RFOs and cyclitol $\alpha$-galactosides (Gal-C) starts in response to seed desiccation process. The initial step involves formation of galactinol $(O-\alpha$-D-galactopyranosyl-( $\rightarrow 1)$-L-myo-inositol) from UDP-D-galactose and myo-inositol by the action of galactinol synthase (GolS, EC 2.4.1.123) (Peterbauer and Richter 2001). Ga- 
lactinol acts as the main galactosyl donor in biosynthesis of RFOs (Keller and Pharr 1996). Low level of myo-inositol in pea seeds limited biosynthesis of galactinol, and in consequence that of RFOs (Karner et al. 2004). Raffinose synthase (RS, EC 2.4.1.82) catalyses transfer of galactosyl residue from galactinol to sucrose forming raffinose (Peterbauer et al. 2002a). Biosynthesis of stachyose from raffinose and galactinol is catalyzed by stachyose synthase (STS, EC 2.4.1.67) (Hoch et al. 1999). Mechanism of verbascose formation is unknown, but probably a multifunctional STS is involved (Peterbauer et al. 2003). Another function of RS from pea seeds is the ability to utilize D-ononitol and D-pinitol instead of sucrose as acceptors of galactose (Peterbauer et al. 2002a). A similar property can be ascribed to STS (Peterbauer et al. 2002b; Hoch et al. 1999). Some of galactosyl cyclitols other than galactinol can be galactose donors for STS as well (Peterbauer et al. 1998). This broad substrate specificity of RS and STS indicate that the same enzyme or a set of enzymes could be engaged in formation of RFOs and Gal-C. Therefore, we can hypothesize, that distribution of galactose moieties between RFOs and Gal$\mathrm{C}$ depends on the concentration of galactose acceptors, like sucrose, RFOs and cyclitols: myo-inositol, its isomers and methyl derivatives.

The concentration of myo-inositol and other cyclitols fluctuate during development and maturation of legume seeds (Górecki et al. 1997; Kuo et al. 1997; Obendorf et al. 1998; Peterbauer et al. 1998). In seeds of some Vicia species, quantitative predominance of D-pinitol over myo-inositol causes a situation in which accumulation of D-pinitol galactosides is preferred to that of RFOs (Lahuta et al. 2005). Levels of cyclitols in seed can be influenced by plant growth conditions because D-pinitol, D-chiro-inositol and $m y o$-inositol can be transported to seeds from maternal tissues (Obendorf et al. 2004; Gomes et al. 2005).

The objective of our research was to determine: 1) the ability of isolated tiny vetch seeds to incorporate exogenously applied D-pinitol and/or D-chiro-inositol (naturally not present in seeds of tiny vetch); 2) the ability of plant explants to transport of D-pinitol and D-chiro-inositol into seeds; 3 ) effect of elevated levels of cyclitols on biosynthesis of their galactosides and RFOs in seeds matured ex planta, and 4) implication of D-chiro-inositol and its galactosides in desiccation tolerance of immature tiny vetch seeds. Because seeds of tiny vetch accumulate RFOs and D-pinitol galactosides, they are a convenient object for studies on a relationship between biosynthesis of both types of carbohydrates (Lahuta et al. 2001).

\section{MATERIALS AND METHODS}

\section{Plant material}

Plants of tiny vetch (Vicia hirsuta [L.] S.F. Gray) were grown in a greenhouse, as described previously (Lahuta et al. 2004). Fully opened flowers were tagged, and pods were taken for determination of fresh weight, dry weight, and germinability and carbohydrate contents at 2-day intervals from 8 to 24 day after flowering (DAF). Three replications containing 20 seeds each were germinated on wet germination paper towels (Anchor Paper Company, St. Paul, MN, USA) at $20^{\circ} \mathrm{C}$ for up to 14 days in the dark. Before the germination test seeds were scarified with a needle under aseptic conditions. Seeds were scored as germinated if the radicle had protruded through the seed coat.

\section{Analysis of raffinose family oligosaccharides (RFOs) and galactosyl cyclitols (Gal-C)}

Content of the RFOs and $\alpha$-galactosides of cyclitols was analyzed by high resolution gas chromatography (HRGC) on a ZEBRON ZB-1 capillary column (Phenomenex, USA; $15 \mathrm{~m}$ length, $0.25 \mathrm{~mm}$ internal diameter and $0.1 \mu \mathrm{m}$ film thicknesses) according to the method described earlier (Górecki et al. 1997) with modification according to Peterbauer et al. (2001). Standards of myo-inositol, glucose, fructose, sucrose, raffinose, stachyose, and xylitol were purchased from Sigma. Standards of D-pinitol and D-chiro-inositol were obtained from Fine Chemicals (New Zeland), galactinol from Wako Pure Chemicals Industries, Ltd. (Japan) and verbascose from Megazyme (Wicklow, Ireland). Commercially unavailable standards of galactosyl pinitols (galactopinitol A, di-galactopinitol A and tri-galactopinitol A) were isolated and purified from seeds of Vicia villosa as described earlier (Szczeciński et al. 2000), and galactosyl chiro-inositols (fagopyritol B1, B2 and B3) were obtained from buckwheat seeds (Steadman et al. 2001). Standard of di-galactosyl myo-inositol (DGMI) was isolated from seeds of Vicia cracca and identified after its acidic hydrolysis to galactose and myo-inositol according to the method described by Kuo (1992). Carbohydrate content was calculated from the ratio of the area of peak of each measured component to the area of internal standard peak (xylitol, Sigma). Content of carbohydrates was calculated from standard curves of the appropriate component. Results of analyses are means of three to five independent replicates \pm SE.

\section{Extraction of soluble protein and assay of activity of galactinol and fagopyritol B1 synthases}

Activities of galactinol synthase (GolS) and fagopyritol B1 synthase (FB1S) were determined according to the method described by Peterbauer et al. (2001) and Ueda et al. (2005) with minor modifications. A sample of mature seeds (approximately $200 \mathrm{mg}$ of fresh weight) was homogenized with a mortar and pestle in $1 \mathrm{~mL}$ of ice-cold extraction buffer ( $\mathrm{pH}$ 7.0, $50 \mathrm{mM}$ HEPES (N-[2-hydroxyethyl] piperazine-N'-[2-ethansulfonic acid])-NaOH, $1 \mathrm{mM}$ dithiothreitol (DTT), 1\% (w/v) polyvinyl polypyrrolidone, and $1 \%$ protease inhibitor cocktail [SIGMA, No. P2714-1EA]) at $4^{\circ} \mathrm{C}$. The homogenate was then centrifuged $(23000 \mathrm{~g}, 30$ $\left.\min , 4^{\circ} \mathrm{C}\right)$. Aliquots of the supernatant $(0.4 \mathrm{~mL})$ were desalted by centrifugal gel filtration (Sephadex G-25 superfine columns, $2 \mathrm{~mL}$ bed volume).

GolS activity was assayed in reaction mixtures $(20 \mu \mathrm{L})$ containing $50 \mathrm{mM}$ HEPES-NaOH (pH 7.0), $1 \mathrm{mM}$ dithiothreitol, $5 \mathrm{mM} \mathrm{MnCl}_{2}, 5 \mathrm{mM}$ UDP-galactose, $20 \mathrm{mM}$ myoinositol and $10 \mu \mathrm{L}$ of the desalted extracts. Reaction mixtures were incubated at $30^{\circ} \mathrm{C}$ for $60 \mathrm{~min}$ and stopped by addition of $70 \mu \mathrm{L}$ of $50 \%$ ethanol and boiling at $100^{\circ} \mathrm{C}$ for 5 min. The amount of galactinol formed (Fig. 1) was determined by HRGC. The effect of myo-inositol concentration on the formation of galactinol was estimated in reaction mixtures (as above) containing myo-inositol at concentrations: $3.33,6.66,13.32$ and $20 \mathrm{mM}$.

Activity of FB1S was estimated in the same way as GolS (Fig. 1), but myo-inositol was replaced by D-chiro-inositol. Other conditions were the same as in the assay of GolS ac- 


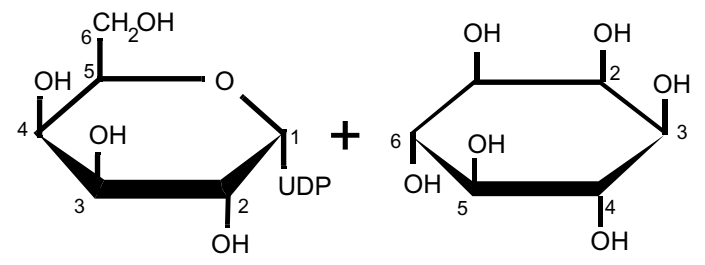

UDP-Galactose

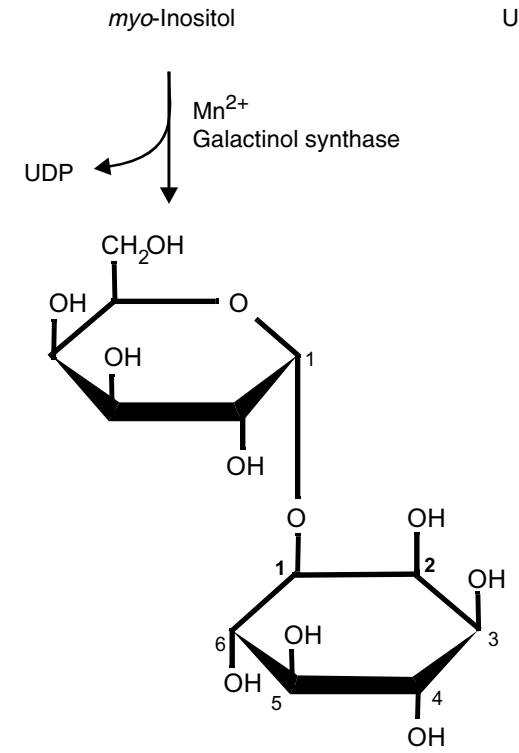

Galactinol

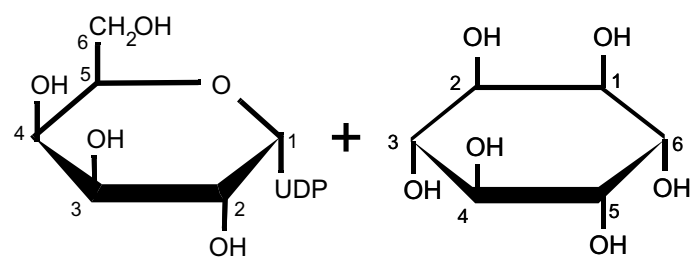

UDP-Galactose

D-chiro-Inositol
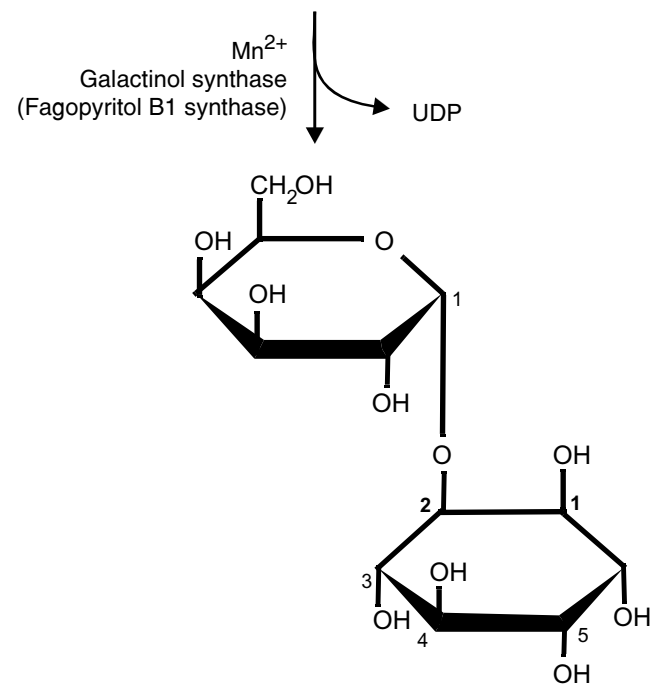

Fagopyritol B1

Fig. 1. Reactions catalyzed by galactinol synthase or fagopyritol B1 synthase.

tivity. Amounts of products of reactions were determined by HRGC method. Activity of GolS (pkat) was expressed as pmol of galactinol or fagopyritol B1 synthesized during 1 second of incubation at $30^{\circ} \mathrm{C}$ by $1 \mathrm{mg}$ of protein in reaction mixture. Soluble protein content was measured using Bradford dye-binding procedure (Bio-Rad protein assay; Bio-Rad, Vienna) with bovine serum albumin as a standard.

\section{Experiment 1 .}

Feeding of isolated seeds with D-chiro-inositol

Seeds of tiny vetch at 14 or 16 DAF were isolated from pods and placed in Petrie dishes ( $5 \mathrm{~cm}$ diameter, 20-30 seeds per treatment, five replicates) in $5 \mathrm{~mL}$ of $50 \mathrm{mM}$ sucrose (control), or in $5 \mathrm{~mL}$ mixture of sucrose and D-chiroinositol, $50 \mathrm{mM}$ each. Seed samples were incubated for 6 days at $19^{\circ} \mathrm{C}$ in a growth chamber $(14 / 10 \mathrm{~h}$, day/night cycle, $200 \mu \mathrm{mol} \mathrm{m} \mathrm{m}^{-2} \mathrm{~s}^{-1}$ light from fluorescent lamps). $\alpha-\mathrm{Ga}-$ lactosides were determined before and after 6 days of incubation. Before analysis seeds were carefully washed with distilled water in order to remove sucrose and cyclitols absorbed on seed coat.

\section{Experiment 2.}

Feeding of tiny vetch explants with D-chiro-inositol and/or D-pinitol

Explants of tiny vetch containing a $3 \mathrm{~cm}$ long stem, one leaf and 6 pods at 16 DAF were prepared. Two explants of tiny vetch (in each of the three replicates) after excision from a plant were immediately transferred to $1.5 \mathrm{~mL} \mathrm{mi-}$ cro-tubes containing $1 \mathrm{~mL}$ of $50 \mathrm{mM}$ sucrose (control) or mixture of sucrose $(50 \mathrm{mM})$ and 10,25 and $50 \mathrm{mM}$ of D-pinitol or D-chiro-inositol.

In the next experiment, mixtures of both cyclitols in 50 $\mathrm{mM}$ sucrose solution were prepared: a) D-pinitol $(50 \mathrm{mM})$ with increased concentration of D-chiro-inositol - 5, 10, 25 and $50 \mathrm{mM}$ or b) $50 \mathrm{mM}$ D-chiro-inositol with increased concentration of D-pinitol - 5, 10 and $25 \mathrm{mM}$. Explants were incubated in a greenhouse at the same temperature and light conditions as the mother plants. After 2-3 days of incubation all culture medium was absorbed by the explants and then pods were subjected to natural, slow drying process during 12 days. In such desiccated and matured seeds RFOs and galactosyl cyclitols were determined.

\section{Experiment 3 .}

The effect of D-chiro-inositol and its galactosides on desiccation tolerance of immature tiny vetch seeds

For this experiment, seeds were isolated from pods at 14 and 16 DAF and incubated for 4 hours in $50 \mathrm{mM}$ sucrose, or sucrose and D-chiro-inositol (both at $50 \mathrm{mM}$ concentration). After washing with distilled water, the seeds were exposed to slow desiccation process. According to the desiccation protocol, every day the humidity of storage atmosphere was lowered, from $92.5 \%$ to $12 \%$, as described earlier (Górecki et al. 1997). Desiccation tolerance was estimated as the ability of dried seeds to germinate. Before germination, seeds were scarified with a needle, humidified over water for $24 \mathrm{~h}$ at $23-24^{\circ} \mathrm{C}$ and germinated on wet paper towels (at $20^{\circ} \mathrm{C}$ for up to 14 days in the dark). 


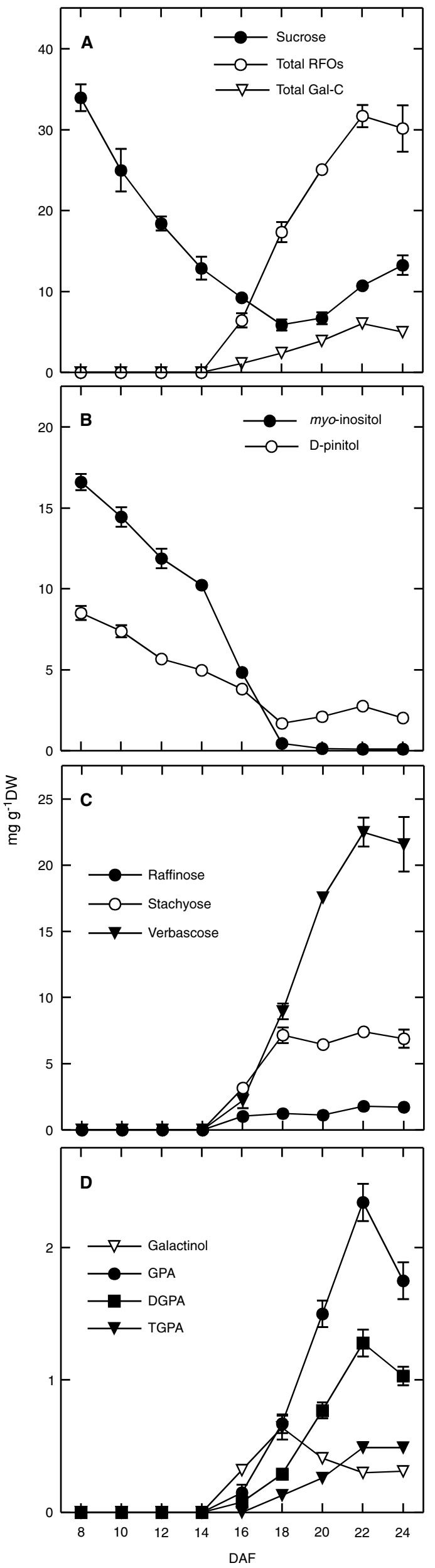

\section{RESULTS}

Accumulation of RFOs and galactosyl cyclitols in vetch seeds matured on plants

At the initial development stages of tiny vetch seeds, sucrose (Fig. 2A), myo-inositol and D-pinitol (Fig. 2B) were quantitatively main carbohydrates, and at 8 DAF their concentrations were 35,16 and $8 \mathrm{mg} \mathrm{g}^{-1} \mathrm{DW}$, respectively. Rapid decline in their levels was observed in growing seed up to 18 DAF. Biosynthesis of galactinol started between 14$-16 \mathrm{DAF}$ and increased over the next four days to the level $0.64 \mathrm{mg} \mathrm{g}^{-1} \mathrm{DW}$ (Fig. 2D). During seed maturation, the concentration of galactinol decreased to $0.31 \mathrm{mg} \mathrm{g}^{-1} \mathrm{DW}$ in mature seeds. Accumulation of raffinose family oligosaccharides (RFOs) and galactosyl pinitols began at 14-16 DAF and continued to seed maturity (Fig. 2C, D). Biosynthesis of galactosyl pinitol A (GPA) and di-galactosyl pinitol A (DGPA) started at the same time as that of galactinol and RFOs, and tri-galactosyl pinitol A (TGPA) appeared 4 days later. Mature seeds of tiny vetch contained 6-fold more of the total RFOs than galactosyl cyclitols (Fig. 2A).

Experiment 1: Seeds at 14 DAF or 16 DAF were taken to the experiment. In seeds collected at 14 DAF galactinol, RFOs and galactosyl pinitols were not found (Fig. 2). After 6 days of incubation in $50 \mathrm{mM}$ sucrose, galactinol and both types galactosides were accumulated (Table 1, left column A). The contents of RFOs and galactosyl pinitols after incubation were similar as in seeds at 16 DAF on planta (Fig. 2C, D). However, during incubation in solution containing $50 \mathrm{mM}$ D-chiro-inositol, the contents of raffinose, stachyose and verbascose were ca three-fold higher than in seeds incubated in sucrose only (Table 1, left column B). Incubation with D-chiro-inositol caused its 2-fold higher accumulation in seeds $\left(19.12 \mathrm{mg} \mathrm{g}^{-1} \mathrm{DW}\right)$ than myo-inositol and D-pinitol. Some D-chiro-inositol was taken to synthesis of its mono- and di-galactosides: fagopyritol B1 and fagopyritol B2. Exogenously applied D-chiro-inositol had no influence on the level of galactosyl pinitols in tiny vetch seeds.

Seeds collected at 16 DAF naturally contained much higher amounts of RFOs than galactosyl pinitols (6.45 and $0.39 \mathrm{mg} \mathrm{g}^{-1} \mathrm{DW}$, respectively) (Fig. 2). After 6 days of incubation of the excised seeds in sucrose, level of the RFOs and galactosyl pinitols increased up to 57.15 and $4.97 \mathrm{mg}$ $\mathrm{g}^{-1} \mathrm{DW}$, respectively (Table 1 , right column A). Seeds incubated in solution contained D-chiro-inositol accumulated the cyclitol (12.15 $\left.\mathrm{mg} \mathrm{g}^{-1} \mathrm{DW}\right)$ and its galactosides: fagopyritols (12.53 $\left.\mathrm{mg} \mathrm{g}^{-1} \mathrm{DW}\right)$. High level of D-chiro-inositol and/or fagopyritols in seeds was accompanied with low content of galactinol and galactosyl pinitols (Table 1, right column B). Total level of the pinitol galactosides was about 2-fold lower in seeds incubated with D-chiro-inositol, than in sucrose only. Concentration of RFOs was similar in both incubation conditions.

Fig. 2. Changes in concentrations of sucrose, total RFOs and total galactosyl cyclitols (A), cyclitols (B), raffinose, stachyose, and verbascose (C), galactinol and galactosyl pinitols (D) during development and maturation of tiny vetch seeds. Abbreviations: GPA - galactopinitol A, DGPA - digalactopinitol A (common name ciceritol), TGPA - trigalactopinitol A. Mean of three measurements. Vertical bars correspond to SE. Where no bars are shown, SE is less than the size of the symbols. 
TABLE 1. Soluble carbohydrates in developing (14 and 16 DAF) tiny vetch seeds incubated for 6 days in $50 \mathrm{mM}$ sucrose (A) or mixture of $50 \mathrm{mM}$ sucrose and $50 \mathrm{mM}$ D-chiro-inositol (B). Means (in $\mathrm{mg} \mathrm{g}^{-1}$ dry weight) for five replicates $\pm \mathrm{SE}$.

\begin{tabular}{|c|c|c|c|c|}
\hline \multirow{3}{*}{ Analyzed carbohydrate } & \multicolumn{2}{|c|}{$14 \mathrm{DAF}$} & \multicolumn{2}{|c|}{$16 \mathrm{DAF}$} \\
\hline & A & $\mathrm{B}$ & A & $\mathrm{B}$ \\
\hline & \multicolumn{4}{|c|}{$\mathrm{mg} \mathrm{g}^{-1} \mathrm{DW}$} \\
\hline Sucrose & $33.00 \pm 3.84$ & $37.54 \pm 8.50$ & $14.83 \pm 1.52$ & $21.62 \pm 1.43$ \\
\hline Total RFOs & $7.12 \pm 1.29$ & $22.79 \pm 6.68$ & $57.15 \pm 8.59$ & $50.87 \pm 10.58$ \\
\hline Raffinose & $0.97 \pm 0.15$ & $3.07 \pm 0.77$ & $2.18 \pm 0.14$ & $4.27 \pm 0.63$ \\
\hline Stachyose & $2.56 \pm 0.65$ & $9.99 \pm 3.40$ & $16.82 \pm 1.91$ & $16.49 \pm 2.33$ \\
\hline Verbascose & $3.59 \pm 0.70$ & $9.74 \pm 3.24$ & $38.15 \pm 6.57$ & $30.11 \pm 8.14$ \\
\hline Galactinol & $0.49 \pm 0.15$ & $0.75 \pm 0.15$ & $3.77 \pm 0.54$ & $2.15 \pm 0.33$ \\
\hline Total cyclitols & $9.89 \pm 0.47$ & $28.00 \pm 1.29$ & $6.18 \pm 0.53$ & $17.41 \pm 0.58$ \\
\hline myo-inositol & $5.63 \pm 0.36$ & $5.19 \pm 0.54$ & $3.19 \pm 0.29$ & $2.86 \pm 0.11$ \\
\hline D-pinitol & $4.26 \pm 0.19$ & $3.68 \pm 0.19$ & $2.99 \pm 0.26$ & $2.40 \pm 0.05$ \\
\hline D-chiro-inositol & - & $19.12 \pm 0.81$ & - & $12.15 \pm 0.51$ \\
\hline Total galactopinitols & $0.96 \pm 0.06$ & $0.82 \pm 0.06$ & $4.97 \pm 0.22$ & $2.78 \pm 0.18$ \\
\hline GPA & $0.33 \pm 0.06$ & $0.32 \pm 0.06$ & $1.93 \pm 0.20$ & $1.27 \pm 0.19$ \\
\hline GPB & $0.22 \pm 0.07$ & $0.18 \pm 0.04$ & $0.44 \pm 0.05$ & $0.26 \pm 0.03$ \\
\hline DGPA & $0.29 \pm 0.07$ & $0.32 \pm 0.07$ & $1.82 \pm 0.25$ & $0.90 \pm 0.19$ \\
\hline TGPA & $0.08 \pm 0.01$ & - & $0.78 \pm 0.16$ & $0.35 \pm 0.06$ \\
\hline Fagopyritol B1 & - & $1.63 \pm 0.32$ & - & $9.37 \pm 1.18$ \\
\hline Fagopyritol B2 & - & 0.300 .15 & - & $3.16 \pm 0.55$ \\
\hline Total & $51.67 \pm 3.11$ & $92.65 \pm 13.24$ & $89.60 \pm 11.73$ & $108.41 \pm 14.09$ \\
\hline
\end{tabular}

Experiment 2: Feeding of tiny vetch explants with sucrose or mixture of sucrose and free cyclitols had large effect on the biosynthesis of RFOs and Gal-C in seeds (Fig. 3). In seeds from explants fed with sucrose alone the concentration of D-pinitol was $4 \mathrm{mg} \mathrm{g}^{-1} \mathrm{DW}$. Addition of D-pinitol to the incubation solution caused high accumulation of the cyclitol, reaching the level of $25 \mathrm{mg} \mathrm{g}^{-1} \mathrm{DW}$ (after incubation in $50 \mathrm{mM}$ D-pinitol), and the content was two-fold higher than RFOs (Fig. 3A, C). In response to elevated concentration of D-pinitol seeds accumulated more mono-galactosyl pinitol A (GPA) (Fig. 3C) and less amounts of digalactosides (stachyose and DGPA). Simultaneously, a dramatic decline in the level of tri-galactosides was noted (verbascose and TGPA) (Fig. 3C, E).

Feeding tiny vetch explants with D-chiro-inositol solutions caused strong inhibition of biosynthesis of RFOs and galactosyl pinitols, and stimulatory effect on fagopyritols formation (galactosides of D-chiro-inositol) (Fig. 3B, D, and F). Incubation with D-chiro-inositol caused much lower concentration of cyclitol in seeds than concentration of D-pinitol after feeding with the cyclitol. The main effect of D-chiro-inositol absorption was the accumulation of its galactosides (fagopyritol B1 and B2) (Fig. 3D). Increasing levels of fagopyritol B1 and B2 was accompanied by declining verbascose content (Fig. 3F). The concentration of galactopinitols (DGPA and TGPA) decreased too (data not shown).

To compare the competition between both cyclitols, tiny vetch explants were fed with mixtures of both compounds. A mixture of $5 \mathrm{mM}$ D-chiro-inositol and $50 \mathrm{mM}$ D-pinitol caused enhanced accumulation of di- and tri-galactosides (stachyose, DGPA, verbascose and TGPA) (Fig. 4A, C). Fagopyritols B1 and B2 were biosynthesized as well (Fig. 4E). A mixture containing higher amounts of D-chiro-inositol than $10 \mathrm{mM}$ inhibited the biosynthesis of RFOs (verbascose, stachyose) and pinitol galactosides (GPA, DGPA and TGPA). Increasing concentration of D-chiro-inositol brought enhanced biosynthesis of its galactosides - fagopyritols B1, B2 and B3.
As a result of feeding tiny vetch explants with $50 \mathrm{mM}$ D-chiro-inositol, accumulation of high levels of fagopyritols and very low amounts of RFOs and galactosyl pinitols was observed (Fig. 3B). D-Pinitol added to $50 \mathrm{mM}$ D-chiro-inositol increased levels of D-pinitol galactosides, and simultaneously depressed the content of fagopyritol B1 (Fig. 4B, D, and F).

\section{Activities of galactinol (GolS) and fagopyritol BI (FB1S) synthases from tiny vetch seeds}

In desalted extracts from mature tiny vetch seeds, activities of galactinol (GolS) and fagopyritol B1 (FB1S) synthases were detected (Fig. 5). Activities of extractable GolS and FB1S increased in response to concentration of myo-inositol in reaction mixture (Fig. 6A, B). Increased content of D-chiro-inositol in reaction mixture containing $6.66 \mathrm{mM}$ myo-inositol caused decline in galactinol synthesis, and enhanced formation of fagopyritol B1, although content of fagopyritol B1 was lower than galactinol (Fig. 6C). In the presence of D-pinitol the activity of GolS decreased too, but synthesis of galactopinitol was not observed (Fig. 6D).

Experiment 3: In seeds excised from pods on 14 DAF, subjected to 4-hour incubation in $50 \mathrm{mM}$ sucrose and then slowly desiccated, enhanced biosynthesis of all galactosides was found: RFOs, galactosyl pinitols and galactosides of myo-inositol (Gal-C) (Table 2). The level of total Gal$\mathrm{C}$ and RFOs was similar (25 and $30 \mathrm{mg} \mathrm{g}^{-1} \mathrm{DW}$, respectively) and quite different in comparison to naturally matured seeds, where concentration of RFOs was ca 6-fold higher than Gal-C (Fig. 2A). Total amounts of all soluble carbohydrates increased from 28 to $73 \mathrm{mg} \mathrm{g}^{-1} \mathrm{DW}$ (before and after slow drying process, respectively). Similar increase in total soluble carbohydrates was observed in slow desiccated seeds, after $4 \mathrm{~h}$ incubation in D-chiro-inositol solution (Table 2C). However, in the presence of D-chiro-inositol, seed accumulated less RFOs and galactosides of 


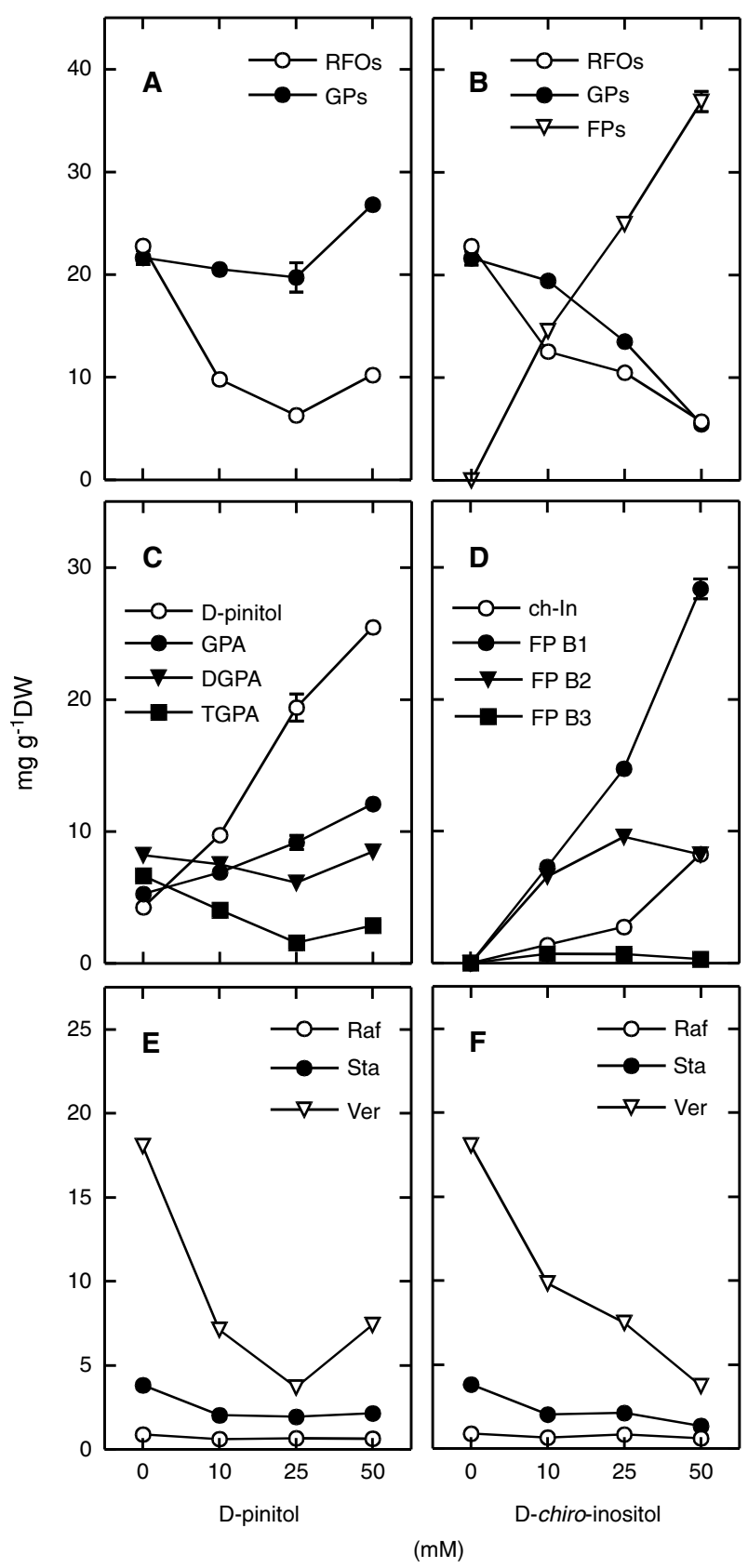

Fig. 3. The effect of exogenous D-pinitol (A, C, E) and D-chiro-inositol (B, D, F) applied in feeding solution on the accumulation of free cyclitols, their galactosides and raffinose family oligosaccharides (RFOs) in tiny vetch seeds matured in pods. Abbreviations: GPS - galactosyl pinitols; $G P A$ - galactopinitol A; DGPA - digalactopinitol A (common name ciceritol); TGPA - trigalactopinitol A; ch-In - D-chiro-inositol; FPs - fagopyritols; FP B1 - fagopyritol B1; FP B2 - fagopyritol B2; FP B3 - fagopyritol B3; Raf - raffinose; Sta - stachyose; Ver - verbascose. Mean of three measurements. Vertical bars correspond to SE. Where no bars are shown, SE is less than the size of the symbols.

myo-inositol. After slow desiccation seed contained more Gal-C than RFOs (29 and $24 \mathrm{mg} \mathrm{g}^{-1} \mathrm{DW}$, respectively).

The accumulation pattern of soluble carbohydrates in slow desiccated seeds from 16 DAF was similar as in seeds from 14 DAF (Table 2). In seeds incubated with of D-chiro-inositol, levels of the myo-inositol galactosides and RFOs were lower than in seeds incubated with sucrose.

Incubation of immature seeds with D-chiro-inositol and further seed slow desiccation had no significant effect on seed desiccation tolerance. Seed without incubation (control) and dried after incubation in cyclitols survived dehy-
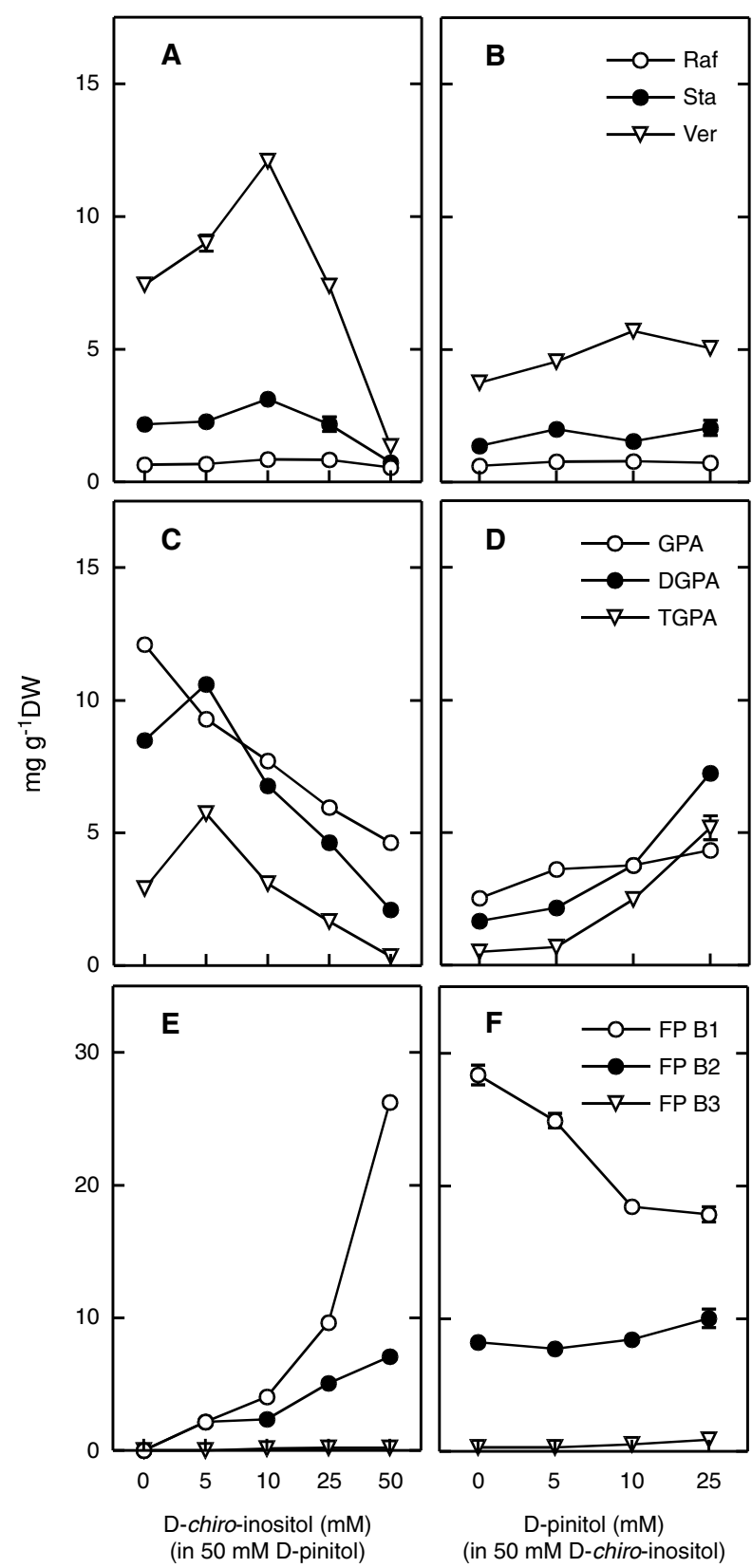

Fig. 4. The effect of increased concentration of D-chiro-inositol in feeding solution (50 mM D-pinitol) (A, C, E) or increased concentration of D-pinitol in $50 \mathrm{mM}$ D-chiro-inositol $(\mathrm{B}, \mathrm{D}, \mathrm{F})$ on the accumulation of raffinose family oligosaccharides (A, B), galactosyl pinitols (C, D) and fagopyritols (E, F). Abbreviations as in Fig. 2. Mean of three measurements. Vertical bars correspond to SE. Where no bars are shown, SE is less than the size of the symbols.

dration at the level 70-90\%. Although the percentage of desiccation tolerant seeds was highest after incubation in D-chiro-inositol (92-98\%), the role of D-chiro-inositol and its galactosides in desiccation tolerance needs further studies.

\section{DISCUSSION}

At the initial development stages tiny vetch seeds contained sucrose and myo-inositol as the main soluble carbohydrates. Similarly to other legumes, during pod filling of tiny vetch levels of both carbohydrates rapidly decreased, and accumulation of galactinol and raffinose family oligosaccharides (RFOs) started (Horbowicz et al. 1995; Frias et 


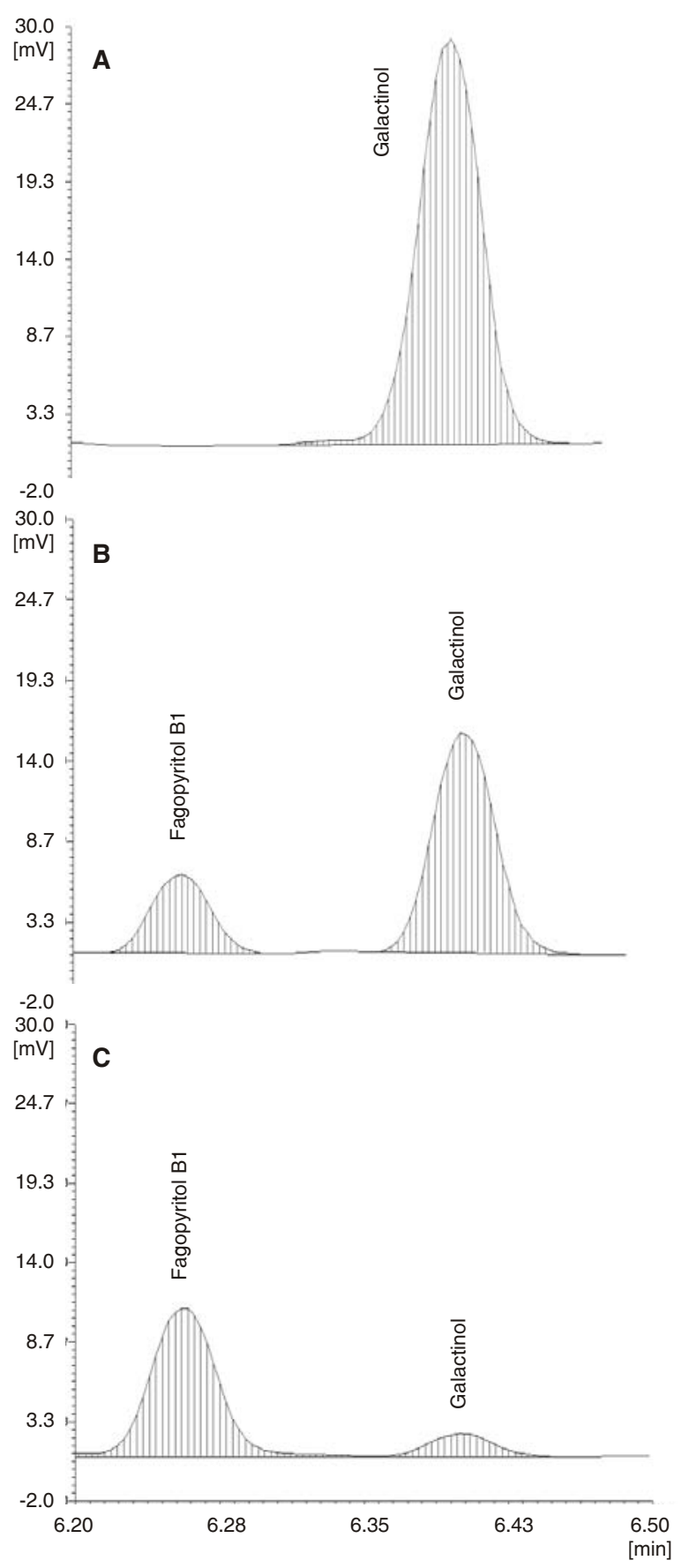

Fig. 5. Gas-chromatogram of TMS-carbohydrates - products of galactinol synthase (GolS) action. GolS synthesizes galactinol from myo-inositol and UDP-galactose (A), or galactinol and fagopyritol B1 (galactosyl chiro-inositol) from mixture of myo-inositol, D-chiro-inositol and UDP-galactose $(\mathrm{B}, \mathrm{C})$ according reaction: UDP-galactose + myo-inositol (D-chiro-inositol) $\rightarrow$ galactinol (fagopyritol B1) + UDP. In Fig. B - ratio of GolS substrates myo-inositol: D-chiro-inositol was 1:3, and in Fig. C was $1: 5$, respectively.

al. 1996; Obendorf et al. 1998; Górecki et al. 2000). Biosynthesis of RFOs, with verbascose as a main galactoside, continued to seed maturity, which is characteristic of all legumes examined (Górecki et al. 1997; Górecki et al. 2000; Lahuta et al. 2000; Peterbauer et al. 2001; Lahuta et al. 2005).

Beside the myo-inositol, young seeds of tiny vetch contained another cyclitol: D-pinitol. Similarly to myo-inositol, concentration of D-pinitol decreased throughout seed maturation. Biosynthesis of D-pinitol galactosides in seeds on planta started at the same time as biosynthesis of RFOs and continued to full seed maturity. However, the final level of mono- di- and tri-galactosyl pinitols was 6-fold lower than RFOs (Fig. 2). Quantitative predominance of myo-inositol over the D-pinitol, and much higher concentration of RFOs than pinitol galactosides confirm our previous hypothesis, that the ratio of D-pinitol and myo-inositol can affect biosynthesis of RFOs and galactosyl pinitols during seed maturation (Lahuta et al. 2005).

The experiment with tiny vetch explants fed with D-pinitol and D-chiro-inositol clearly showed the ability of the plant to transport of both cyclitols through the stem and pods, and to accumulate in seeds. Increased level of D-pinitol in seed caused enhanced biosynthesis of its mono-galactoside (GPA), but not that of di- and tri-galactosides: DGPA and TGPA (Fig. 3C). Simultaneously, there was inhibited biosynthesis of verbascose and, to a lesser extent, stachyose. It can mean that high concentration of D-pinitol inhibited the activity of synthases of di- and tri-galactosides, and/or galactinol synthase which produces galactinol, indispensable for biosynthesis of RFOs. Multifunctional stachyose synthase (STS) from pea seed can form verbascose in two ways: one way utilizes stachyose and galactinol, and the other one uses two stachyose molecules (Peterbauer et al. 2003). These authors have found that STS additionally can utilize D-pinitol instead of raffinose as galactosyl acceptor, although yield of the process was low. The data shown in this paper indicate that high concentration of myo-inositol can inhibit the STS activity. Thus, we suppose that high level of D-pinitol had an inhibitory effect on STS in tiny vetch seeds. On the other hand, we have noticed that high concentration of D-pinitol inhibits the galactinol synthase (GolS) from mature seed of tiny vetch as well (Fig. 6D). Extracts from tiny vetch seeds were not able to form of galactosyl pinitol A (GPA) from UDP-galactose and D-pinitol, but biosynthesis of GPA was possible with galactinol as galactosyl donor (data not shown). Crude extracts from pea (Frydman and Neufeld 1963) or purified or recombinant GolS from soybean (Obendorf et al. 2004), buckwheat (Ueda et al., 2005) and pea seeds (Karner et al. 2004) demonstrated similar substrate specificity. The inhibitory effect of D-pinitol on galactinol synthase found in tiny vetch seed caused low level of galactinol, and in effect much lower accumulation of di- and tri-galactosides.

Extractable galactinol synthase (GolS) from tiny vetch seeds formed galactoside of D-chiro-inositol (fagopyritol B1), which in nature does not occur in seed of vetch species. Similar properties are possessed by GolS from buckwheat seeds (Ueda et al. 2005), and soybean seeds (Obendorf et al. 2004). However, biosynthesis of fagopyritol B1 and A1 in buckwheat seed was a result of the activity of two distinct forms of galactinol synthase (FeGolS1 and FeGolS2, respectively) (Ueda et al. 2005). During the present study we have found that isolated, immature tiny vetch seeds (14-16 DAF) fed for 6 days with D-chiro-inositol formed its mono- and di-galactosides: fagopyritol B1 and B2, but not fagopyritol A1 (Table 1). Short (4 h) incubation with the same solution of D-chiro-inositol and further slow desiccation procedure caused similar effect (Table 2). It seems that Gol-S from tiny vetch has similar properties as FeGolS1 from buckwheat seed (Ueda et al. 2005). D-chiroInositol was transported into the seed similarly to D-pinitol, and converted to appropriate galactosides (Fig. 3B, D, and F). However, high concentration of D-chiro-inositol 


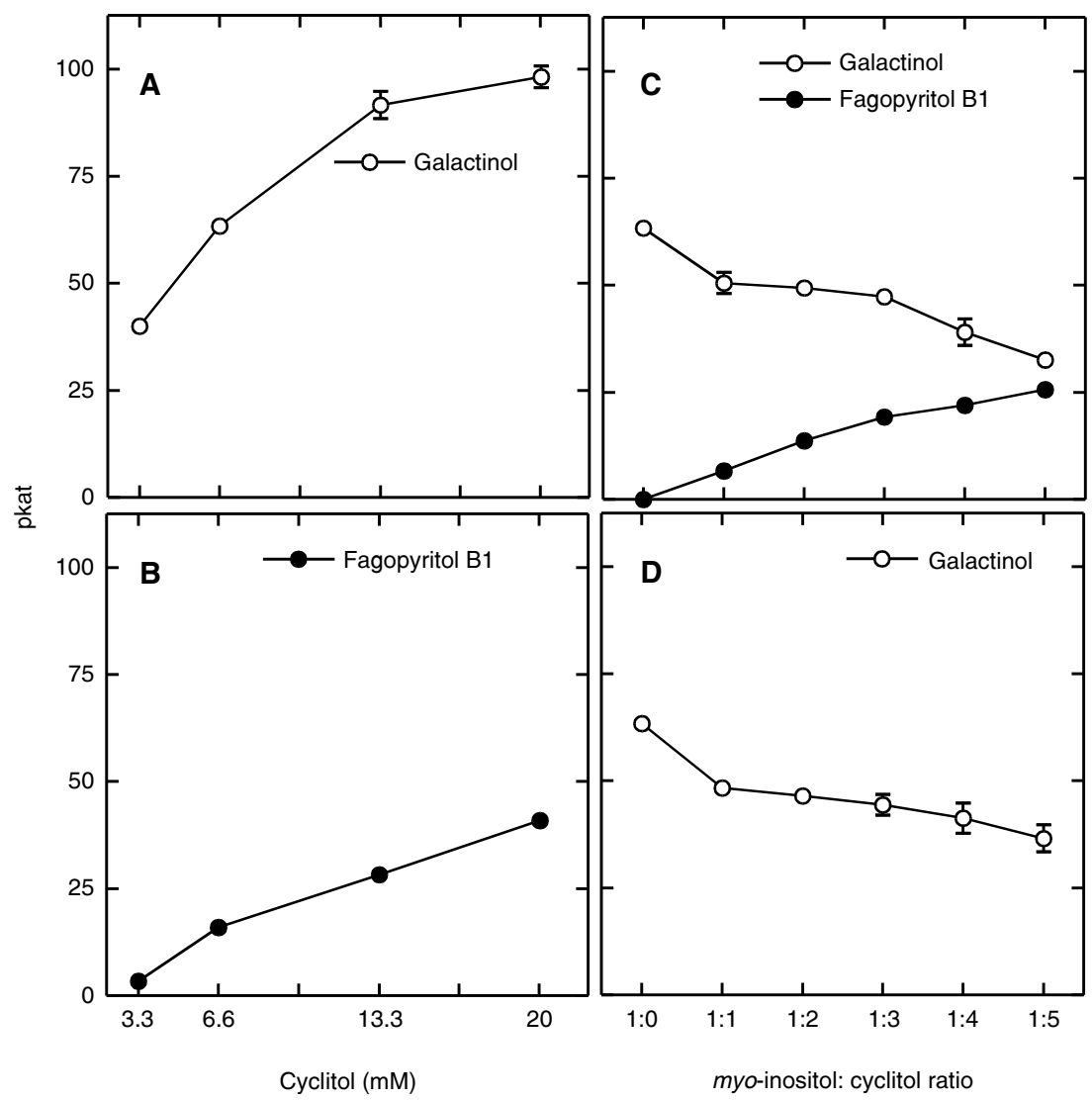

Fig. 6. The effect of increased concentration of myo-inositol or D-chiro-inositol on the activity of extractable GolS, which produces galactinol (A) or fagopyritol B1 (B). GolS substrate (myo-inositol and D-chiro-inositol) competition (C) and inhibitory effect of D-pinitol on galactinol formation (D). Mean of three measurements. Vertical bars correspond to SE. Where no bars are shown, se is less than the size of the symbols.

TABLE 2. Soluble carbohydrates in tiny vetch seeds (collected at 14 and 16 DAF) before (A) and after slow desiccation (B and C). Seeds prior desiccation were incubated for $4 \mathrm{~h}$ in $50 \mathrm{mM}$ sucrose (B) or mixture of $50 \mathrm{mM}$ sucrose and $50 \mathrm{mM}$ D-chiro-inositol (C). Means for five replicates \pm SE. Desiccation tolerance was expressed as a percentage of dried seeds able for germination.

\begin{tabular}{|c|c|c|c|c|c|c|}
\hline \multirow{4}{*}{ Analyzed carbohydrate } & Before desiccation & \multicolumn{2}{|c|}{ After slow desiccation } & Before desiccation & \multicolumn{2}{|c|}{ After slow desiccation } \\
\hline & \multicolumn{3}{|c|}{$14 \mathrm{DAF}$} & \multicolumn{3}{|c|}{$16 \mathrm{DAF}$} \\
\hline & A & B & $\mathrm{C}$ & A & B & $\mathrm{C}$ \\
\hline & \multicolumn{3}{|c|}{$\mathrm{mg} \mathrm{g}^{-1} \mathrm{DW}$} & \multicolumn{3}{|c|}{$\mathrm{mg} \mathrm{g}^{-1} \mathrm{DW}$} \\
\hline Sucrose & $12.90 \pm 1.39$ & $13.07 \pm 0.36$ & $14.86 \pm 0.42$ & $8.51 \pm 0.90$ & $10.99 \pm 0.57$ & $14.44 \pm 0.25$ \\
\hline $\begin{array}{l}\text { Total sucrose galactosides } \\
\text { (RFOs) }\end{array}$ & 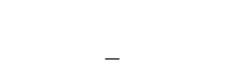 & $30.45 \pm 1.02$ & $23.93 \pm 0.88$ & $6.45 \pm 0.87$ & $37.50 \pm 1.53$ & $26.34 \pm 0.94$ \\
\hline Cyclitols & $15.19 \pm 0.22$ & $3.71 \pm 0.22$ & $1.40 \pm 0.25$ & $8.66 \pm 0.45$ & $1.93 \pm 0.05$ & $0.89 \pm 0.06$ \\
\hline Total galactosyl cyclitols: & - & $25.52 \pm 1.00$ & $29.34 \pm 2.25$ & $1.15 \pm 0.08$ & $20.05 \pm 0.57$ & $25.38 \pm 0.72$ \\
\hline galactosides of: $m y o$-inositol & - & $10.96 \pm 1.12$ & $6.29 \pm 0.32$ & $0.76 \pm 0.07$ & $9.39 \pm 0.52$ & $6.24 \pm 0.12$ \\
\hline D-pinitol & - & $14.57 \pm 0.41$ & $13.31 \pm 0.52$ & $0.39 \pm 0.07$ & $10.67 \pm 0.32$ & $11.15 \pm 0.22$ \\
\hline D-chiro-inositol & - & - & $9.72 \pm 0.65$ & - & - & $7.99 \pm 0.12$ \\
\hline Total soluble carbohydrates & $28.10 \pm 1.52$ & $72.76 \pm 1.86$ & $69.52 \pm 2.58$ & $24.78 \pm 2.05$ & $70.47 \pm 2.17$ & $67.04 \pm 1.85$ \\
\hline Germination (\%) & $80.00 \pm 13.24$ & $69.82 \pm 9.84$ & $92.62 \pm 4.34$ & $91.67 \pm 8.34$ & $90.00 \pm 5.78$ & $98.33 \pm 1.67$ \\
\hline
\end{tabular}

and/or fagopyritols caused much higher inhibition of RFOs biosynthesis in tiny vetch seeds than the D-pinitol did.

Competition between D-chiro-inositol and D-pinitol as acceptors of galactose was clearly observed in our feeding experiments. Constant level of D-pinitol in feeding solution and increasing concentration of D-chiro-inositol promoted formation of fagopyritols and inhibited biosynthesis of galactopinitols. On the contrary, increasing concentration of D-pinitol in solution containing constant level of D-chiro-inositol $(50 \mathrm{mM})$ caused enhanced accumulation of galactosyl pinitols, and inhibited formation of fagopyritols. As a result of equal concentration of both cyclitols, accumulation of fagopyritols rather than galactopinitols was preferred. High concentration of both cyclitols drastically inhibited biosynthesis of verbascose and stachyose.
For reasons unknown to today GolS of tiny vetch seed favors biosynthesis of fagopyritol B1 instead of galactinol. Low amounts of galactinol were not sufficient for synthesis of stachyose and verbascose. Moreover, a possibility that there exists a multifunctional enzyme or a set of enzymes which can utilize various substrates: sucrose, free cyclitols, and even their galactosides, can further complicate the situation (Peterbauer et al. 2002a).

Young seeds of legumes contain D-pinitol and D-chiro-inositol, but their levels were several-fold lower than the level of myo-inositol and sucrose (Horbowicz et al. 1995; Górecki et al. 1997). Therefore, maturing seeds of such species produce much more raffinose family oligosaccharides (RFOs) than galactosyl cyclitols. In feeding experiments we changed the proportions between the D-pinitol 
and/or D-chiro-inositol and myo-inositol, and in effect matured seed contained more cyclitol galactosides than RFOs. The results of our experiments indicated that high concentration of D-pinitol and/or D-chiro-inositol diminished formation of RFOs in tiny vetch seeds. The observations confirm recently obtained data for buckwheat (Obendorf et al. 2004), and soybean seeds (Gomes et al. 2005). In both species synthesis of free D-pinitol and D-chiro-inositol in embryo tissues was not observed. Thus, the transport of cyclitols from the mother plant into developing seeds can play a pivotal role in the regulation of biosynthesis of both groups of galactosides. Seeds of Vicia species which contain free D-pinitol in vegetative tissues (our unpublished data) accumulate D-pinitol galactosides (Lahuta et al. 2005). Similarly, D-pinitol or D-pinitol and D-chiro-inositol occurring in plants of chickpea, yellow lupine and soybean are present as free cyclitols and as galactosyl cyclitols in mature seeds (Ford 1984; Górecki et al. 1997; Kuo et al. 1997; Horbowicz et al. 1998; Hoch et al. 1999). The same situation was found in the case of D-ononitol and galactosyl ononitol in Vigna umbellata (Wanek and Richter 1997; Peterbauer et al. 1998) and L-bornesitol and galactosyl bornesitol (lathyritol) in Lathyrus odoratus (Obendorf et al. 2005). It is possible that changes in proportions between concentrations of cyclitols in vegetative tissues of plants can reflect biosynthesis of their $\alpha$-galactosides in seeds. Verification of this suggestion needs more studies.

\section{ACKNOWLEDGMENTS:}

This work was supported by grant No 3P04C 03622 from the Ministry of Scientific Research and Information Technology of Poland.

\section{LITERATURE CITED}

FRIAS J., VIDAL-VALVERDE C., KOZŁOWSKA H., GÓRECKI R., HONKE J., HEDLEY C.L. 1996. Evolution of soluble carbohydrates during the development of pea, faba bean and lupin seeds. Z. Lebens.-Unters. Forsch. 203: 27-32.

FRYDMAN R.B., NEUFELD E.F. 1963. Synthesis of galactosylinositol by extracts from peas. Bioch. Biophys. Res. Comm. 12: $121-125$.

FORD C.W. 1984. Accumulation of low molecular weight solutes in water stressed tropical legumes. Phytochemistry 23: 1007-1015.

GOMES C.I., OBENDORF R.L., HORBOWICZ M. 2005. myoInositol, D-chiro-inositol, and D-pinitol synthesis, transport, and galactoside formation in soybean explants. Crop Sci. 45 (4): 1312-1319

GÓRECKI R.J., PIOTROWICZ-CIEŚLAK A.I., LAHUTA L.B., OBENDORF R.L. 1997. Soluble carbohydrates in desiccation tolerance of yellow lupin seeds during maturation and germination. Seed Sci. Res., 7: 107-115.

GÓRECKI R.J., LAHUTA L.B., JONES A.D., HEDLEY C.L. 2000. Soluble sugars in maturing pea seeds of different lines in relation to desiccation tolerance. In: M. Black, K.J. Bradford, J. Vasquez-Ramos (eds), Seed Biology: Advances and Applications. CAB International, Wallingford, UK, pp. 67-74.

HOCH G., PETERBAUER T., RICHTER A. 1999. Purification and characterization of stachyose synthase from lentil (Lens culinaris) seeds: galactopinitol and stachyose synthesis. Arch. Biochem. Biophys. 366: 75-81.
HORBOWICZ M., OBENDORF R.L. 1994. Seed desiccation tolerance and storability: Dependence on flatulence-producing oligosaccharides and cyclitols - review and survey. Seed Sci. Res. 4: 385-405.

HORBOWICZ M., OBENDORF R.L., MC KERSIE B., VIANDS D.R. 1995. Soluble saccharides and cyclitols in alfalfa (Medicago sativa L.) somatic embryos, leaflets, and mature seeds. Plant Sci. 109: 191-198.

HORBOWICZ M., BRENAC P., OBENDORF R.L. 1998. Fagopyritol B1, $O$ - $\alpha$-D-galactopyranosyl-( $1 \rightarrow 2)$-D-chiro-inositol, a galactosyl cyclitol in maturing buckwheat seeds associated with desiccation tolerance. Planta, 205: 1-11.

KARNER U., PETERBAUER T., RABOY V., JONES D.A., HEDLEY J.C., RICHTER A. 2004. myo-Inositol and sucrose concentrations affect the accumulation of raffinose family oligosaccharides in seeds. J. Exp. Bot. 55: 1981-1987.

KELLER F., PHARR D.M. 1996. Metabolism of carbohydrates in sinks and sources: galactosyl-sucrose oligosaccharides. In: E. Zamski, A.A. Schaffer (ed.) "Photoassimilate distribution in plants and crops. Source-sink relationships" Marcel Dekker, Inc., pp 157-183.

KUO T.M. 1992. Isolation and identification of galactinol from castor oilseed meal. J. Am. Oil. Chem. Soc. 69: 569-574.

KUO T.M., LOWELL C.A., SMITH P.T. 1997. Changes in soluble carbohydrates and enzymatic activities in maturing soybean seed tissues. Plant Sci. 125: 1-11.

LAHUTA L.B., ŁOGIN A., REJOWSKI A., SOCHA A., ZALEWSKI K. 2000. Influence of water deficit on the accumulation of sugars in developing field bean (Vicia faba var. minor) seeds. Seed Sci. Technol. 28: 93-100.

LAHUTA L.B., GÓRECKI R.J., HOŁDYŃSKI C., HORBOWICZ M. 2001. The seeds of genus Vicia (Leguminosae) as an object for study on metabolism of raffinose series of oligosaccharides and galactosyl cyclitols. Abstract of 4th European AEP Conference on Grain Legumes, Cracow, Poland, pp. 366$-367$.

LAHUTA L.B., GÓRECKI R.J., GOJŁO E., HORBOWICZ M. 2004. Effect of exogenous abscisic acid on accumulation of raffinose family oligosaccharides and galactosyl cyclitols in tiny vetch seeds (Vicia hirsuta [L.] S.F. Gray). Acta Soc. Bot. Pol. 73: 277-283.

LAHUTA L.B., GÓRECKI R.J., GOJŁO E., HORBOWICZ M. 2005. Differences in accumulation of soluble $\alpha$-galactosides during seed maturation of several Vicia species. Acta Physiol. Plant. 27 (2): 163-171.

OBENDORF R. 1997. Oligosaccharides and galactosyl cyclitols in seed desiccation tolerance. Seed Sci. Res. 7: 63-74.

OBENDORF R.L., HORBOWICZ M., DICKERMAN A.M., BRENAC P., SMITH M.E. 1998. Soluble oligosaccharides and galactosyl cyclitols in maturing soybean seeds in planta and in vitro. Crop Sci. 38: 78-84.

OBENDORF R.L., ODORCIC S., UEDA T., COSEO M.P., VASALLO E. 2004. Soybean galactinol synthase forms fagopyritol B1 but not galactopinitols: substrate feeding of isolated embryos and heterologous expression. Seed Sci. Res. 14: 321-333.

OBENDORF R.L., MCINNIS C.E., HORBOWICZ M., KERESZTES I., LAHUTA L.B. 2005. Molecular structure of lathyritol, a galactosylbornesitol from Lathyrus odorathus seeds, by NMR. Carbohydr. Res. 340: 1441-1446.

PETERBAUER T., RICHTER A. 1998. Galactosylononitol and stachyose synthesis in seeds of adzuki bean. Purification and characterization of stachyose synthase. Plant Physiol. 117: 165-172.

PETERBAUER T., PUSCHENREITER M., RICHTER A. 1998. Metabolism of galactosylononitol in seeds of Vigna umbellata. Plant Cell Physiol. 39: 334-341.

PETERBAUER T., RICHTER A. 2001. Biochemistry and physiology of raffinose family oligosaccharides and galactosyl cyclitols in seeds. Seed Sci. Res. 11: 185-197. 
PETERBAUER T., LAHUTA L.B., BLÖCHL A., MUCHA J., HEDLEY C.L., GÓRECKI R.J., RICHTER A. 2001. Analysis of the raffinose family oligosaccharide pathway in pea seeds with contrasting carbohydrate composition. Plant Physiol. 127: 1764-1772.

PETERBAUER T., MACH L., MUCHA J., RICHTER A. 2002a. Functional expression of cDNA encoding pea (Pisum sativum L.) raffinose synthase, partial purification of the enzyme from maturing seeds, and steady-state kinetic analysis of raffinose synthesis. Planta, 215: 839-846.

PETERBAUER T., MUCHA J., MACH L. RICHTER A. $2002 \mathrm{~b}$. Chain elongation of raffinose in pea seeds. Isolation, characterization, and molecular cloning of a multifunctional enzyme catalyzing the synthesis of stachyose and verbascose. J. Biol. Chem. 277: 194-200.

PETERBAUER T., KARNER U., MUCHA J., MACH L., JONES D.A., HEDLEY C.L., RICHTER A. 2003. Enzymatic control of the accumulation of verbascose in pea seeds. Plant Cell Environ. 26: 1385-1391.
STEADMAN K.J., FULLER D.J., OBENDORF R.L. 2001. Purification and molecular structure of two digalactosyl D-chiroinositols and two trigalactosyl D-chiro-inositols from buckwheat seeds. Carbohydr. Res. 331: 19-25.

SZCZECINSSKI P., GRYFF-KELLER A., HORBOWICZ M., LAHUTA L.B. 2000. Galactosylpinitols isolated from vetch (Vicia villosa Roth.) seeds. J. Agric. Food Chem. 48: $2717-$ $-2720$.

UEDA T., COSEO M.P., HARRELL T.J., OBENDORF R.L. 2005. A multifunctional galactinol synthase catalyzes the synthesis of fagopyritol A1 and fagopyritol B1 in buckwheat seed. Plant Sci. 168: 681-690.

WANEK W., RICHTER A. 1997. Biosynthesis and accumulation of d-ononitol in Vigna umbellata in response to drought stress. Physiol. Plant. 101: 416-424.

YASUI T., ENDO Y., OHASHI H., 1987. Infrageneric variation of the low molecular weight carbohydrate composition of the seeds of genus Vicia (Leguminosae). Bot. Mag. Tokyo, 100: 255-272. 